\title{
Entre o ensino e a vocação: dificuldades enfrentadas pelos professores da rede estadual e municipal de Colmeia/TO
}

Between teaching and vocation: difficulties faced by the teachers of the state and municipal network of COLMEIA / TO

\author{
Welton Cardoso \\ Mateus Santos Silva \\ Aluisio Vasconcelos de Carvalho \\ Júlio Cesar Ibiapina Neres \\ Izidorio Paz Fernandes Neto
}

\begin{abstract}
Resumo: A escolha de uma profissão é um dos momentos mais importantes na vida pessoal, algumas pessoas buscam conciliar a profissão dos seus sonhos com 0 mercado de trabalho. Várias pesquisas com professores da rede pública de ensino têm relatado uma alta demanda com transtornos relacionados aos níveis de estresse, muitas vezes ocasionados pelo excesso de trabalho que transpassa o ambiente escolar. O presente estudo foi desenvolvido na cidade de Colmeia, situada no Estado do Tocantins, com 42 professores de ambos os sexos das escolas estaduais e municipais da região, atuantes na sala de aula, com a idade mínima de 20 anos. 0 artigo teve como abordagem principal fazer uma correlação entre o exercício da profissão como uma vocação ou uma escolha circunstancial e, fazer um paralelo dos níveis de estresse desenvolvido em ambas as situações. Os resultados apontaram vários motivos que estão associados ao adoecimento dos docentes atuantes na educação e ensino, demonstrando que a profissão professor exerce um grande esforço para a sua efetiva execução.
\end{abstract}

Palavras-chave: Estresse; Vocação; Professor; Escola.

Abstract: Choosing a profession is one of the most important moments in your personal life, some people seek to reconcile the profession of their dreams with the job market. Several surveys of public school teachers have reported a high demand for disorders related to stress levels, often caused by overwork that permeates the school environment. The present study was developed in the city of Colmeia, located in the State of Tocantins, with 42 teachers of both sexes from state and municipal schools in the region, working in the classroom, with the minimum age of 20 years. The main approach of the article was to make a correlation between the exercise of the profession as a vocation or a circumstantial choice and to compare the levels of stress developed in both situations. The results pointed out several reasons that are associated with the illness of teachers working in education and teaching, demonstrating that the teaching profession exerts a great effort for its effective execution.

Keywords: Stress; Vocation; Teacher; School.

\section{Introdução}

A escolha de uma profissão é um dos momentos mais importante na vida de algumas pessoas buscam conciliar a profissão dos seus sonhos com o 
mercado de trabalho (LISBOA, 2002). De acordo com Barreto (2000), a escolha profissional afeta o estilo de vida e interfere na satisfação laboral e pessoal. A satisfação profissional envolve os aspectos pessoais, vocacionais, voltado ao conceito do trabalho (BARDAGI, 2006). Harkness e Super (1996) afirmam que a satisfação profissional da pessoa vem da percepção de que o trabalho é a compreensão do seu conhecimento, ou seja, o indivíduo através da sua profissão pode apresentar os seus valores, interesses e seu traço de personalidade, por isso a satisfação pode ser caracterizada como sentimento de identificação com sua profissão escolhida. As alterações das obrigações do professor na sociedade ecoam no modo de ensino e na saúde do educador (ROCHA, 2008).

Segundo a Organização Mundial de Saúde, OMS (2011), as doenças consideradas ocupacionais possuem causas que decorrem de vários fatores, que podem concorrer para determinados níveis de estresse. E de acordo com a associação Brasileira para Prevenção de acidentes, doenças relacionadas ao stress são as principais causas de afastamento do trabalho escolar (LIPP, 2003). Quando o profissional se sente desmotivado, vem à exaustão emocional, normalmente caracterizada pela falta de energia, podendo levar ao baixo desempenho em suas atividades. A baixa realização profissional pode ser caracterizada como uma sensação de que tem se alcançado pouco e o que é feito não possui valor (CHERNISS, 1980a; WORLD HEALTH ORGANIZATION, 1998).

Dados das Nações Unidas enfatizam que em 2050 a densidade populacional mundial estará elevada e em condições que levarão a existir um maior nível de pessoas com transtornos mentais, como a ansiedade e o estresse. Segundo Faragher et al. (2005), o baixo grau de bem-estar com o trabalho realizado causa problemas psicológicos tais como ansiedade, depressão e estresse que possuem uma grande associação entre si.

Realizado por Cury (2001), uma pesquisa com professores da rede pública de ensino diagnosticou que $92 \%$ dos docentes do país sofrem com transtornos relacionados aos níveis de estresse. fatores, como: superlotação das salas de aula, comportamento inadequado dos acadêmicos, falta de 
capacitação profissional em sua área e até questões da sua vida pessoal levam o professor brasileiro a desanimar de sua profissão (LIMA, 1998).

Inúmeros professores apresentam mudanças em seu estado de saúde tanto físico e mental, doenças que envolvem seus sistemas musculares e esqueléticos (CARDOSO et al., 2009), suas vozes sofrem alterações (DELCOR et al, 2004, LUCHESI et al., 2009), apresentam distúrbio do sono, falha de memória e estresse (GOULART Jr.; LIPP, 2008; POCINHO; CAPELO, 2009; VEDOVATO; MONTEIRO, 2008). Portanto, os problemas psíquicos aparentam os principais causadores de abandono do trabalho.

Devido à baixa remuneração, os docentes estendem sua carga horária em jornada dupla de trabalho (BAIÃO et al., 2013). As consequências dessa dupla jornada podem ser diversificadas, pois sobrecarrega o profissional da educação, podendo provocar fadiga física ou até BURNOUT (CNSDSS, 2008). Lipp e Tanganelli (2002) afirmam que podem ocorrer inúmeras evidências, trazendo à tona condições de estresse: tensões musculares, doenças como gastrites e úlcera, hiperacidez estomacal, ansiedade, esquecimento, irritabilidade excessiva, distúrbios do sono, sensação de incompetência entre outros.

A referente pesquisa possui como objetivo averiguar os sintomas que levam os professores da rede estadual e municipal da cidade de Colmeia a um quadro de estresse, fazendo uma correlação entre os sintomas desenvolvidos em profissionais que exercem sua função por meio de vocação profissional e aos que estão na carreira de professor por uma questão circunstancial, e desta forma estabelecer parâmetros entre idade, tempo de serviço e vocação profissional, com transtornos de cunho físico e psicológico, desenvolvidos ao longo de sua vida profissional, a fim de identificar uma suposta relação de causa e consequência.

Desse modo é necessário desenvolver conhecimento científico nas pesquisas envolvendo a saúde do professor, dando enfoque na sua opção profissional, se eles exercerão o poder de escolha profissional e se esse fator influenciou na saúde do educador. 


\section{Material e métodos}

\section{Caracterização da área de estudo}

O presente trabalho foi desenvolvido na cidade de Colmeia situada no Estado do Tocantins nas escolas estaduais e municipais da região (Figura 1). O Município de Colmeia está localizada, na região norte do Tocantins, (IBGE 2010). Trata-se de uma localidade que conta com 6 escolas que serviram de base para coleta de dados e desenvolvimento do referente trabalho. As escolas que oferecem ensino fundamental I são elas: CEAS - Centro Educacional Arte do saber (particular), Escola Municipal Marechal Humberto de Alencar Castelo Branco, Escola Municipal Josefina Ribeiro Dos Santos e Escola Estadual Juscelino Kubitschek de Oliveira. Já o ensino fundamental II é ofertado pela as Unidades de Ensino Escola Estadual Ary Ribeiro Valadão Filho e Colégio Estadual Serra das cordilheiras, o ensino médio é todo ofertado pela U.E. Serra das Cordilheiras.

\section{Métodos de coleta de dados da pesquisa exploratória de campo.}

Entre as muitas técnicas de coletas de dados, no presente trabalho foi utilizado do questionário.

Segundo Gil (1999, p.128)

Esse questionário pode ser caracterizado como, técnica de
investigação formada por um número mais ou menos elevado
de questões que pode ser apresentado por escrito ou por
opções de múltipla escolha para as pessoas, tendo como
principal objetivo o conhecimento de crenças, sentimentos,
interesses, expectativas, situações vivenciadas entre outros.
Com isso essa técnica serve para saber as informações da
realidade que se deseja estudar.

Esse modelo foi escolhido, pois atinge grande número de pessoas, comparado com outros modelos, permite $\mathrm{o}$ anonimato de quem está respondendo às perguntas, além de da liberdade da pessoa responder no momento que ela achar melhor e são de fácil compreensão.

Este estudo foi desenvolvido com 42 professores entre os sexos feminino e masculino, atuantes na sala de aula, com a faixa etária oscilando entre 20 - 51 anos, com o tempo de docência de 5 - 21 anos. Foram excluídos da pesquisa profissionais que estavam atuando em outras funções do ambiente 
escolar e professores que estavam na sala de aula sem terem formação na área da docência.

A coleta de dados quantitativos e qualitativas ocorreu pela aplicação do questionário que contou com perguntas abertas e fechadas. Durante a pesquisa as respostas foram registradas por meio do questionário respondido pelos professores atuantes na sala de aula, na cidade de Colmeia.

\section{Resultados e discussão}

O questionário para identificação dos níveis de estresse em professores da cidade de Colmeia teve como primeira pergunta a idade do docente, com as seguintes informativas, de 20 a 30 anos que totalizaram uma porcentagem de $9,5 \%$ equivalente a quatro professores, de 31 a 40 anos que totalizaram uma porcentagem de $38 \%$ equivalente a dezesseis professores, de 41 a 50 anos que totalizaram uma porcentagem de $43 \%$ equivalente a dezoito professores e acima de 51 anos de idade que totalizaram 9,5\% equivalente a 4 professores. A resposta pode ser observada logo abaixo na tabela 1.

Tabela 1: Resultado sobre as idades dos professores.

\section{IDADE DOS PROFESSORES}

\begin{tabular}{ccc}
\hline Respostas & Qtd. de respostas & Porcentagem adquirida \\
& & \\
\hline 20 a 30 ANOS & 04 & $9,5 \%$ \\
31 a 40 ANOS & 16 & $38 \%$ \\
41 a 50 ANOS & 18 & $43 \%$ \\
\hline ACIMA DE 51 ANOS & 04 & $9,5 \%$ \\
\hline
\end{tabular}

Fonte: os autores

Dados semelhantes ao de Valério et al. (2009), que fez sua pesquisa com esses profissionais com idades de 30 a 51 anos de idade, onde constatou que os maiores níveis de estresse estavam entre professores de 31 a 40 anos. Mazon et al. (2008) relata em seu trabalho que a média de idade dos docentes 
que apresentam níveis altos de estresse está na faixa dos 38 anos. Para Valério et al. (2009), a literatura não faz uma correlação entre o desenvolvimento da doença e a idades do indivíduo que venha adquirir o estresse.

Na segunda pergunta foi abordada sobre a quantidade de anos de profissão em sala de aula, com as seguintes opções informativas: até cinco anos de trabalho, de 6 a 10 dez anos, de 11 a 15 anos, de 16 a 20 anos e acima de 21 anos trabalhados, dos 42 profissionais questionados, 6 responderam que tem até 5 anos de trabalho, correspondendo um percentual de $14 \%$; 6 professores responderam que tem de 6 à 10 anos de trabalho totalizando uma porcentagem de 14\%; 8 profissionais marcaram que tem de 11 à 15 de trabalho correspondendo um percentual de 19\%; 10 professores marcaram que tem entre 16 a 20 anos de trabalho o que corresponde $24 \% ; 12$ professores responderam que tem acima de 21 anos de trabalho correspondendo $29 \%$ dos profissionais questionados, conforme representado na tabela 2.

Tabela 2: resposta do segundo questionamento, quantidade de anos de profissão.

\section{QUANTIDADE DE ANOS DE PROFISSÃO}

\begin{tabular}{ccc}
\hline Respostas & Qtd. de respostas & Porcentagem adquirida \\
& & \\
\hline ATÉ 05 ANOS & 06 & $14 \%$ \\
06 a 10 ANOS & 06 & $14 \%$ \\
11 a 15 ANOS & 08 & $19 \%$ \\
16 a 20 ANOS & 10 & $24 \%$ \\
\hline ACIMA DE 21 ANOS & 12 & $29 \%$ \\
\hline
\end{tabular}

Fonte: os autores

Em estudos feitos por Carlotto et al., (2006) "Síndrome de Burnout e fatores associados: um estudo epidemiológico com professores" é constatado uma média de idade em experiência profissional de 13 anos de atuação na 
área, enquanto o obtido por essa pesquisa mostra que os professores da cidade de Colmeia, que foram acometidos com tais síndromes têm entre 05 anos de trabalho e acima de 21 anos, um resultado que se assemelha com o encontrado é o de (VALÉRIO et al., 2009), Segundo Valério et al. (2009), o surgimento de tais síndromes não se deve somente ao tempo que o professor exerce sua profissão, há vários outros fatores promovedores do estresse.

Questionados sobre a sua profissão na terceira pergunta, se sua área de atuação profissional é resultado de uma escolha vocacional, as respostas dos 42 profissionais foram as seguintes: 29 professores responderam que sim, que o exercício de sua profissão é fruto de uma vocacional; 13 professores disseram que não, exercem a profissão, mas aspiravam trabalhar em outra área distinta da educação. Os docentes que atuam na educação por vocação correspondem a $69 \%$ e os que exercem a profissão, mas não têm a educação como vocação totalizam $31 \%$ do total de 42 professores questionados. Como pode ser observado na tabela 3 abaixo.

Tabela 3: respostas da terceira pergunta resultado da escolha profissional

\begin{tabular}{ccc}
\hline SUA ÀREA DE ATUAÇÃO PROFISSIONAL É RESULTADO DE UMA ESCOLHA \\
VOCACIONAL?
\end{tabular}

Fonte: os autores

De acordo com De Sá Moura (2011, p.40).

Pensamos que a motivação com relação à escolha profissional pode se revelar como um fator fundamental processo saúde/doença. Analisando a evolução da Profissão docente, podemos constatar que os sujeitos que escolhiam essa profissão tinham um dom, uma vocação, sem contar que a profissão era considerada um sacerdócio. Hoje, os tempos são outros, talvez pela falta de melhores ou de outras oportunidades no mercado de trabalho, a escolha profissional está bastante limitada. Diante disso, alguns sujeitos escolhem seguir a carreira docente sem amar a profissão, sem uma compreensão das atribuições da atividade e como irão face às condições e exigências da profissão.

De acordo com Rippel et al. (2017), que cerca de $70 \%$ dos professores pesquisados em seu trabalho mencionaram que fizeram a escolha pela 
docência mediante a vocação, e somente $30 \%$ disseram ter escolhido a carreira de professor pela grande oferta de vagas de serviço e pelo baixo preço dos cursos voltados para licenciatura.

Perguntados na quarta questão sobre o desânimo e a falta de vontade de trabalhar, as respostas dos 42 professores foram as seguintes: 8 falaram que nunca sentiram desanimados, o que corresponde $19,04 \%$ dos professores; 32 falaram que às vezes sentem-se desanimados, não tem vontade de ir para escola, o que totaliza um percentual de $76,20 \%$ dos questionados; 2 professores responderam que frequentemente sentem desanimados e não tem vontade de ir para escola, o que corresponde um percentual de $4,76 \%$ dos profissionais que responderam o questionário, conforme mostra a tabela 4.

Tabela 04: resposta da quarta pergunta, sobre desânimo e vontade de não ir trabalhar.

\section{AO PENSAR EM TRABALHAR, VOCÊ SENTE UM GRANDE DESÂNIMO, VONTADE} DE NÃO IR?

\begin{tabular}{ccc}
\hline Respostas & Qtd. de respostas & Porcentagem adquirida \\
& & \\
Frequentemente & 02 & $4,76 \%$ \\
Às vezes & 32 & $76,20 \%$ \\
Nunca & 08 & $19,04 \%$ \\
\hline
\end{tabular}

Fonte: os autores

De acordo com Thiele et al. (2009), as condições do ambiente escolar voltado para o bem-estar do educador exercem impactos direto em suas condições de trabalho e qualidades de vida, e abrindo vias que previne e proporciona saúde ao corpo docente, dando-Ihes satisfação laboral, fazendo com que o professor exerça sua função com criatividade e empenho.

Questionados, na quinta pergunta, sobre a motivação em desempenhar o seu papel enquanto docente, onde as respostas seria "sim" ou "não" dos 42 dos professores pesquisados, 33 marcaram que sim, sentem-se motivados em desenvolver seu papel, totalizando um percentual de $78,57 \%$ e somente 9 professores responderam que não, não se sentem motivados no exercício de suas funções, totalizando um percentual de $21,43 \%$. 
Tabela 05: sentimento de motivação ao desempenhar a função

\begin{tabular}{ccc}
\hline \multicolumn{3}{c}{ SENTE-SE MOTIVADO EM DESEMPENHAR O SEU PAPEL ENQUANTO } \\
PROFESSOR?
\end{tabular}

Fonte: os autores

Segundo estudo realizado por Dejours (1994) o reconhecimento é necessário para que o professor se sinta valorizado, caso contrário pode gerar um quadro de desmotivação, pois quanto mais o trabalhador se sentir valorizado maior será sua iniciativa e criatividade. Mosqueira (2001) diz que o desgaste e os problemas que fazem parte dessa profissão são fatores que levam os professores a sentirem-se desmotivados e insatisfeitos.

Os docentes foram questionados na sexta pergunta se durante o seu período de atuação docente, desenvolveram algum tipo de transtorno psicológico (como estresse, ansiedade...) que esteja diretamente ligado a sua profissão. Dos 42 profissionais, 27 responderam que sim, desenvolveram algum transtorno psicológico, totalizando um percentual de 64,30\%; e 15 professores responderam que não, não desenvolveram nem um tipo de transtorno psicológico, totalizando um percentual de 35,70\%. Para esses 15 professores a pesquisa foi encerrada, embora 2 desses docentes tenham continuado a responder o questionário, conforme exposto na tabela 05.

Tabela 06: Desenvolvimento de transtorno no exercício da profissão.

\begin{tabular}{|c|c|c|}
\hline \multicolumn{3}{|c|}{$\begin{array}{c}\text { SE DURANTE O SEU PERÍODO DE ATUAÇÃO DOCENTE, DESENVOLVEU ALGUM } \\
\text { TIPO DE TRANSTORNO PSICOLÓGICO (COMO ESTRESSE, ANSIEDADE...) QUE } \\
\text { ESTEJA DIRETAMENTE LIGADO A SUA PROFISSÃO. }\end{array}$} \\
\hline Respostas & Qtd. de respostas & Porcentagem adquirida \\
\hline Sim & 27 & $64,30 \%$ \\
\hline Não & 15 & $35,70 \%$ \\
\hline
\end{tabular}

Fonte: os autores

Esteves (1995) relata que a docência deveria ser muito prazerosa, mas é um dos trabalhos que mais levam exaustão psicológica e emocional. 
Mesquita (2013) obteve em seu trabalho dados semelhantes, onde ocorreu uma predominância de $46,37 \%$ de professores que tinham sintomas psicológicos relacionados ao estresse. Goulart (2008) em sua pesquisa constatou que cerca de $60 \%$ dos professores pesquisados por ele podem ter problemas psicológicos.

Para os 29 professores que responderam a questão de número 6,0 questionário continuou para a interrogativa número 7 , que abordava a influência das manifestações de estresse no seu desempenho profissional. Assim 18 professores disseram que sim, o estresse interfere em seu desempenho profissional, que dá um percentual de $62,06 \%$ dos professores que opinaram; 9 responderam que não, o estresse não interfere em seu desempenho profissional, dando um percentual de 31,03\%; e 2 professores resolveram não opinar, correspondendo um total de 6,9\%, dos pesquisados.

Tabela 07: manifestações do estresse

\begin{tabular}{ccc}
\hline AS MANIFESTAÇÕES DE STRESS AFETAM SEM DESEMPENHO PROFISSIONAL \\
\hline Respostas & Qtd. de respostas & Porcentagem adquirida \\
Sim & 18 & $62,06 \%$ \\
Não & 09 & $31,04 \%$ \\
Não opinaram & 02 & $6,9 \%$ \\
\hline
\end{tabular}

Fonte: os autores

Segundo Contaifer et al., (2003)

\begin{abstract}
Estudos realizados no ambiente acadêmico colocam em destaque a ocorrência de situações estressantes a que vem prejudicarem o desempenho e a saúde do docente, colocando em risco o efetivo desenvolvimento do ensino. São frequentes as reclamações dos docentes em relação a estarem vivenciando períodos de estresse, com manifestações de sintomas associados, que os tem prejudicado no que se refere ao desempenho pessoal e principalmente profissional.
\end{abstract}

No oitavo questionamento feito, os docentes marcaram as opções que descrevem seu estado de saúde psicológico ou físico. As sugestões foram tensão muscular, hiperacidez estomacal, esquecimento de coisas corriqueiras, irritabilidade excessiva, sensação de incompetência e distúrbio do sono. 21 professores responderam que sofriam com tensões musculares, o que 
corresponde $72,41 \%$ dos questionados; 7 professores marcaram que sofrem com hiperacidez estomacal, correspondendo um percentual de $24,14 \%$ dos questionados; 14 professores responderam que sofrem de esquecimento de coisas corriqueiras, o que corresponde um percentual de $48,27 \%$ dos questionados; 15 professores responderam sentem irritabilidade excessiva, correspondendo um percentual de $51,72 \%$ dos questionados; 7 professores responderam que sente uma sensação de incompetência, totalizando um percentual de $24,14 \%$ dos questionados; 15 professores marcaram que sentem o distúrbio do sono, dando um percentual de $51,72 \%$ de professores acometidos por esse sintoma. Nesse questionário os profissionais puderam marcar mais de uma opção. Os resultados poderão ser observados na tabela 06 logo abaixo.

Tabela 08: estado de saúde psicológico ou físico

\section{MARQUE TODAS AS OPÇÕES QUE DESCREVEM SEU ESTADO DE SAÚDE PSICOLÓGICO OU FÍSICO}

\begin{tabular}{ccc}
\hline Respostas & Qtd. de respostas & Porcentagem adquirida \\
Tensão Muscular & 21 & $72,41 \%$ \\
Hiperacidez Estomacal & 07 & $24,14 \%$ \\
$\begin{array}{c}\text { Esquecimento de coisas } \\
\text { corriqueiras }\end{array}$ & 14 & $48,27 \%$ \\
Irritabilidades Excessivas & 15 & $51,72 \%$ \\
$\quad \begin{array}{c}\text { Sensação de } \\
\text { Incompetência }\end{array}$ & 07 & $24,14 \%$ \\
Distúrbio do sono & 15 & $51,72 \%$ \\
\hline
\end{tabular}

Fonte: os autores

Para Contaifer et al. (2003, p. 217)

Fisiologicamente os estressores são capazes de disparar em nosso organismo uma série de reações via sistema nervoso, relacionadas com o funcionamento dos órgãos e regulação das emoções. Existem estudos indicativos de relações entre o estresse ocupacional e algumas doenças, tais como: hipertensão, úlceras gástricas, úlceras duodenais, infarto agudo do miocárdio e vários distúrbios mentais, que incapacitam o trabalhador.

A nova pergunta questionava se os profissionais fizeram ou fazem algum tipo de tratamento psicológico. Desses, 9 responderam que sim, o que chega a um percentual de apenas $31,03 \%$ dos questionados; 20 professores 
responderam que não, não fizeram nem fazem algum tipo de tratamento psicológico, o que corresponde um percentual de $68,97 \%$ dos docentes questionados. Resultados na tabela 07.

Tabela 09: Tratamento psicológico

\begin{tabular}{ccc}
\hline \multicolumn{2}{c}{ PROFISSIONAIS QUE FIZERAM OU FAZEM ALGUM TRATAMENTO PSICOLÓGICO } \\
\hline Respostas & Qtd. de respostas & Porcentagem adquirida \\
Sim & 09 & $31,03 \%$ \\
Não & 20 & $68,97 \%$ \\
\hline \multicolumn{4}{c}{}
\end{tabular}

Fonte: os autores

O questionário mostra que poucos profissionais têm se preocupado em buscar ajuda de profissionais especializados em tratamento psicológicos. A literatura aborda a importância de desenvolver políticas voltadas à prevenção e ao tratamento das síndromes estressivas. Para Lipp e Goulart Júnior (2008) há uma necessidade imprescindível de efetivação de políticas que abordem tanto a prevenção como o tratamento do estresse ocupacional, além de aumentar a motivação do trabalho docente. Carloto (2002) ressalta em seu trabalho que é necessárias ações que venham prevenir o estresse, e que essas ações devem ser promovidas em conjunto, instituições, professores, alunos e a sociedade, para modificar esse quadro.

Na décima e última pergunta, os professores foram questionados sobre o fator que mais se aproxima ao fator causador de seus problemas de estresse, as alternativas foram à falta de realização profissional /vocação, falta de valorização/reconhecimento por parte da sociedade de modo geral, esgotamento físico por excesso de trabalho, e outros. Entre essas interrogações somente 01 professor respondeu que a falta de realização profissional é o fator causador do seu problema de estresse, esse profissional corresponde a $3,46 \%$ dos que responderam o questionário. Enquanto os que marcaram que a falta de valorização/reconhecimento é o fator causador foram 9 professores, o que corresponde $31,03 \%$ dos pesquisados; os que marcaram esgotamento físico por excesso de trabalho foram 14, corresponde $48,27 \%$ dos professores; e 05 professores responderam que são outros os fatores causadores de estresse, o que corresponde a um total de $17,24 \%$ dos professores. 
Tabela 10: Fator causador do estresse.

\begin{tabular}{ccc}
\hline O FATOR QUE MAIS SE APROXIMA AO FATOR CAUSADOR DE SEUS PROBLEMAS & $\begin{array}{c}\text { PE ESTRESSE } \\
\text { Qtd. de respostas }\end{array}$ & Porcentagem adquirida \\
\hline Respostas & 01 & $3,46 \%$ \\
$\begin{array}{c}\text { Falta de realização } \\
\text { profissional / vocação }\end{array}$ & 09 & $31,03 \%$ \\
$\begin{array}{c}\text { Falta de valorização } \\
\text { profissional I } \\
\text { reconhecimento }\end{array}$ & 14 & $48,27 \%$ \\
$\begin{array}{c}\text { Esgotamento físico I } \\
\text { excesso de trabalho } \\
\text { Outros }\end{array}$ & 05 & $17,24 \%$ \\
\hline
\end{tabular}

Fonte: os autores

Para De Oliveira Santos et al. (2010, p.249), as condições inadequadas de trabalho, a falta de recursos, materiais, pessoais e incentivos, contribuem para que o ambiente laboral seja um local estressante, tendo influência direta no serviço prestado pelo trabalhador.

Segundo Jiménez et al. (1994), o docente sente o esgotamento emocional no momento que não pode ajudar seus alunos, mostrando assim despersonalização, sentindo também baixa realização pessoal.

Ao abordar a relação entre o exercício da profissão como uma atividade vocacional ou circunstancial e, fazer um paralelo dos níveis de estresse desenvolvidos nas situações supracitadas, verificou-se que apenas $3,46 \%$ dos professores que responderam à pesquisa consideram que os níveis de estresse estejam relacionados diretamente com sua escolha ou aptidão profissional.

Verificou-se que em sua grande maioria, os docentes pesquisados demonstraram poder de escolha e até mesmo vocação profissional, porém sendo surpreendidos ao longo de sua jornada docente, com inúmeros fatores externos que o levam a desanimar de sua profissão e a desenvolver problemas de saúde relacionados ao estresse e excesso de trabalho. 


\section{Conclusão}

Tais fatores nos levam a concluir que a docência por si só é uma profissão estressante, elevando a probabilidade de desenvolver vários transtornos, relacionados potencialmente às condições de trabalho escolar. Situações estas que podem baixar a qualidade de vida do professor e o seu próprio rendimento enquanto profissional. Um ponto preocupante da pesquisa está relacionado ao percentual de profissionais que afirmam ser acometidos por algum transtorno relacionado ao estresse, diretamente associado à atividade docente, mas que não busca tratamento ou ajuda de um especialista em saúde psicológica.

Com isso, constatamos que é necessário o desenvolvimento e aplicação efetiva de ações diretamente voltadas para a saúde do professor, visando à prevenção e o tratamento das causas do estresse, que dirigidas por parte das autoridades competentes, representarão um avanço na qualidade da educação nacional.

\section{Referências}

BARRETO, M. A. M. A importância de uma escolha profissional adequada para a realização pessoal dos indivíduos: Algumas considerações. Revista Ciências da Educação, v. 2, n. 3, p. 177-185, 2000.

BARDAGI, M., Lassance, M. C. P., Paradiso, Â. C., \& de Menezes, I. A. Escolha profissional e inserção no mercado de trabalho: percepções de estudantes formandos. Psicologia escolar e educacional, v. 10, n. 1, 2006.

BARDAGI, M. P., \& Paradiso, Â. C. Trajetória acadêmica e satisfação com a escolha profissional de universitários em meio de curso. Revista Brasileira de Orientação Profissional, v. 4, n. 1-2, p. 153-166, 2003.

BAIÃO, L. D. P. M., \& Cunha, R. G. Doenças e/ou disfunções ocupacionais no meio docente: uma revisão de literatura. Formação@ Docente, v. 5, n. 1, 2013.

BRASIO, K. M., Laloni, D. T., Fernandes, Q. P., \& de Lima Bezerra, T. Comparação entre três técnicas de interveção psicológica para tratamento da fibromialgia: treino de controle de stress, relaxamento progressivo e reestruturação cognitiva. Revista de Ciências Médicas, v. 12, n. 4, 2012.

CARDoso, H. C., Bueno, F. C. D. C., Mata, J. C. D., Alves, A. P. R., Jochims, I., Vaz Filho, I. H. R., \& Hanna, M. M. Avaliação da qualidade do sono em estudantes de Medicina. Rev. bras. educ. méd, v. 33, n. 3, p. 349-355, 2009. 
CARLOTTO, M. S., \& Palazzo, L. D. S. Síndrome de burnout e fatores associados: um estudo epidemiológico com professores. Cadernos de Saúde Pública, v. 22, p. 1017-1026, 2006.

CARLOTTO, Mary Sandra. A síndrome de Burnout e o trabalho docente. Psicol. estud., Maringá, v. 7, n. 1, jun. 2002. Disponível em <http://www.scielo.br.php?script=sci_arttext\&pid=

S141373722002000100005\&Ing=pt\&nrm=iso>. Acessos em 09 de setembro de 2019.

CANOVA, K. R., \& Porto, J. B. O impacto dos valores organizacionais no estresse ocupacional: um estudo com professores de ensino médio. RAM. Revista de Administração Mackenzie, v. 11, n. 5, p. 4-31, 2010.

PINOTTI, S. A. G. Stress no professor: fontes, sintomas e estratégias de controle. Revista Brasileira Multidisciplinar, 2005, 9.2: 207-216.

COMISSÃO NACIONAL SOBRE DETERMINANTES SOCIAIS DA SAÚDE (CNSDSS). As causas sociais das iniquidades em saúde no Brasil/Causes of social inequities in Brazil. Editora Fiocruz Rio de Janeiro. 216 p. 2008

CONTAIFER, T. R. C., Bachion, M. M., Yoshida, T., \& de Souza, J. T. Estresse em professores universitários da área de saúde. Revista Gaúcha de Enfermagem, v. 24, n. 2, p. 215, 2003.

DA BOA, S. V. D. R., \& Deps, V. L. Prevenção e tratamento do estresse e da síndrome de burnout em professores da rede pública de ensino. linkscienceplace-Interdisciplinary Scientific Journal, v. 2, n. 1, 2015.

DE ARAÚJO, T. M., \& Carvalho, F. M. Condições de trabalho docente e saúde na Bahia: estudos epidemiológicos. Educação \& Sociedade, v. 30, n. 107, p. 427-449, 2009.

DE LARA, L. D., \& de Araújo, M. C. S. O adolescente e a escolha profissional: compreendendo o processo de decisão. Arquivos de Ciências da Saúde da UNIPAR, v. 9, n. 1, 2005.

DELCOR, N. S., Araújo, T. M., Reis, E. J., Porto, L. A., Carvalho, F. M., Silva, M. O., ... \& Andrade, J. M. D. Condições de trabalho e saúde dos professores da rede particular de ensino de Vitória da Conquista, Bahia, Brasil Cadernos de Saúde Pública, v. 20, p. 187-196, 2004.

DE SÁ MOURA, P. R. Saúde, sofrimento e estresse na profissão docente. Mal-Estar e Sociedade, v. 4, n. 7, p. 33-55, 2011.

DEJOURS, C., Abdoucheli, E., Jayet, C., \& Betiol, M. I. S. Psicodinâmica do trabalho: contribuições da escola dejouriana à análise da relação prazer, sofrimento e trabalho. São Paulo: Atlas, 1994.

ESTEVE, J. M. Mudanças sociais e função docente. Profissão professor, 1995, 2: 93-124. 
FARAGHER, E. B., Cass, M., \& Cooper, C. L. The relationship between job satisfaction and health: a meta-analysis. Occupational and environmental medicine, 2005, 62.2: 105-112.

GIL, Antônio Carlos. Métodos e técnicas de pesquisa social. 5. ed. São Paulo: Atlas, 1999.

GOMES, A. R., Silva, M. J., Mourisco, S., Silva, S., Mota, A., \& Montenegro, N. Problemas e desafios no exercício da actividade docente: Um estudo sobre o stresse," burnout", saúde física e satisfação profissional em professores do $3^{\circ}$ ciclo e ensino secundário. Revista Portuguesa de Educação, 2006v. 19, n. 1, p. 67-93.

GOULART JUNIOR, E., \& Lipp, M. E. N. Estresse entre professoras do ensino fundamental de escolas públicas estaduais. Psicologia em estudo, 2008. p. 847-857

HARKNESS, S., \& Super, C. M. (Eds.). Parents' cultural belief systems: Their origins, expressions, and consequences.. Guilford Press, 1996.

LAWLER, E. E. Motivation in work organizations. Monterey: Brooks/Cole. 1973.

LOCKE, E. A. What is Job Satisfaction? Organizational Behavior and Human Light at the End of the Tunnel. Psychological Science, 1969, 1.4: 240-246.

LIPP, M. E. N.; NOVAES, L. E. Stress Do Professor (o). Papirus Editora, 2003.

LIMA, M. E. A. O significado do trabalho humano. In: CARVALHO, A. O. (Org.). Administração contemporânea: algumas reflexões. Belo Horizonte: UFMG, p.78-103, 1998.

MAZON, V., Carlotto, M. S., \& Câmara, S. Síndrome de Burnout e estratégias de enfrentamento em professores. Arquivos Brasileiros de Psicologia, 2008, v. 60 , n. 1 , p. $55-66$.

MESQUITA, A. A., Gomes, D. S., Lobato, J. L., Gondim, L., \& de Souza, S. B. (2013). Estresse e síndrome de burnout em professores: Prevalência e causas. Psicologia Argumento, 2013, v. 31, n. 75.

MOURA, C. B., \& Silveira, J. M. Orientação profissional sob o enfoque da análise do comportamento: avaliação de uma experiência. Estudos de Psicologia, 2002, 19.1: 5-14.

MOSQUERA, J. J. M.; STOBÄUS, C. D. O mal-estar na docência: causas e consequências. Revista da ADPPUCRS, Porto Alegre, nov. 2001, n. 2, p. 2334.

NÓVOA, A., Huberman, M., Goodson, I., Holly, M., Moita, M., \& Gonçalves, J. Vidas de professores. American Sociological Review, 1995, 49.1: 100-116. 
ORGAN, D. W. The motivational basis of organizational citizenship behavior. Research in organizational behavior, 1990, 12.1: 43-72.

OLIVEIRA, J. M. S. Um estudo sobre as causas do stress dos professores de educação infantil, da rede municipal de Lauro de Freitas, em sala de aula. $61 \mathrm{f}$. 2012. Projeto de pesquisa apresentado ao curso de Pedagogia da Faculdade Integrada-UNIBAHIA, Lauro de Freitas, Bahia.

OMS - ORGANIZAÇÃO MUNDIAL DE SAÚDE. About WHO. Genebra: OMS, 2011. Disponível em: http://www.who.int/topics/mental health/es/. Acesso em: 19 setembro 2019.

PAGGIARO, P. B. S., \& Calais, S. L. Estresse e escolha profissional: um difícil problema para alunos de curso pré-vestibular. Contextos clínicos, 2009, 2.2: 97-105..

RIPPEL, C. B., Borba, S. H., Steffen, L. B., \& Longen, W. C. Paradigmas do trabalho docente: percepção de professores municipais afastados ou readaptados por estresse sobre os fatores causais. Inova Saúde, 2017, 6.1: 208-225.

ROSA, C. D., \& Carlotto, M. S. Síndrome de Burnout e satisfação no trabalho em profissionais de uma instituição hospitalar. Revista da SBPH, 2005, 8.2: 115.

ROCHA, V. M. D., \& Fernandes, M. H. Qualidade de vida de professores do ensino fundamental: uma perspectiva para a promoção da saúde do trabalhador. Jornal Brasileiro de Psiquiatria. Rio de Janeiro. Vol. 57, no. 1 (jan./mar. 2008), p. 23-27.

SAVATER, F. (2003). El valor de elegir.

SERVILHA, E. A. M. Estresse em professores universitários na área de fonoaudiologia. Revista de Ciências Médicas, 2012 v. 14, n. 1.

SHARMA, R. D., \& Jyoti, J. Job satisfaction among school teachers. IIMB Management Review, 2006, 18.4: 349-363.

SCHAFFER, R. H. Job satisfaction as related to need satisfaction in work. Psychological monographs: General and applied, 1953, 67.14: 1.

VALÉRIO, F. J., Amorim, C., \& Moser, A. M. A síndrome de Burnout em professores de Educação Física. Revista de Psicologia da IMED, 2009, 1.1: 127-136.

ZILLE, L. P., \& Cremonezi, A. M. Estresse no trabalho: um estudo com professores da rede pública estadual de Minas Gerais. Revista Reuna, 2013, 18.4: 111-128.

DE OLIVEIRA Santos, A. F., \& Cardoso, C. L. Profissionais de saúde mental: estresse e estressores ocupacionais stress e estressores ocupacionais em saúde mental. Psicologia em estudo, 2010, 15.2: 245-253. 


\section{Sobre os Autores}

\section{Welton Cardoso}

welton_cardoso26@hotmail.com

Licenciado em Ciências Biológicas, IESC/Faculdade Guaraí.

Mateus Santos Silva

mateussant563@gmail.com

Licenciado em Ciências Biológicas, Instituto Educacional Santa Catarina/Faculdade Guaraí.

\section{Aluisio Vasconcelos de Carvalho}

aluisiovasconcelos@gmail.com

Licenciado em Biologia, especialista em Educação Ambiental e Desenvolvimento Sustentável, Análises clínicas e Zoologia, mestre em Ciências do Ambiente e especialização em andamento em Fitoterapia e Análises clínicas veterinária. Atualmente é Professor Adjunto do IESC/Faculdade Guaraí nos cursos de Biomedicina, Ciências Biológicas, Pedagogia e Zootecnia.

\section{Júlio Cesar Ibiapina Neres}

jcneres@gmail.com

Possui graduação em Ciências Biológicas pela Universidade Estadual do Piauí (2001) e Mestrado em Ciências Ambientais e Saúde pela Pontifícia Universidade Católica de Goiás (2008). Atualmente, sou Professor e Coordenador do Curso de Ciências Biológicas, modalidade Licenciatura do Instituto Educacional Santa Catarina, Faculdade Guaraí. Acumulando o cargo de Servidor Público Estadual na SEDUC do Estado do Tocantins, exercendo o cargo de Professor da Disciplina de Biologia, no ensino Médio, lotado no Centro de Ensino Médio Oquerlina Torres, Guaraí TO. Integrante do Banco de Avaliadores do Sistema Nacional de Avaliação da Educação Superior BASis/INEP (MEC) e Colaborador Voluntário do Grupo de Estudos em Democracia e Gestão Social da UNESP (GEDGS).

\section{Izidorio Paz Fernandes Neto}

Izidorio.paz@hotmail.com

Possui graduação em Pedagogia pelo Instituto Educacional Santa Catarina, Faculdade Guaraí (2015). Especialista em Administração e Inspeção Escolar pela Universidade Cândido Mendes (2016). Mestrando do PPGE- Ensino da Universidade do Vale do Taquari- UNIVATES/RS. Professor da Rede Municipal de Ensino de Guaraí-Tocantins e Professor dos cursos de Pedagogia e Ciências Biológicas do Instituto Educacional Santa Catarina/IESC- FAG. 